\title{
EDUCAÇÃO AMBIENTAL TRANSFORMADORA, CRÍTICA E REVOLUCIONÁRIA ATRAVÉS DA EDUCOMUNICAÇÃO
}

\author{
Francisco Pontes de Miranda Ferreira ${ }^{1}$
}

\section{Resumo}

A degradação ambiental é consequência de um complexo de fatores que inclui o próprio capitalismo e a modernidade. As relações sociais de produção necessitam ser questionadas e transformadas. A educação ambiental crítica deve trabalhar para a construção de novos paradigmas diferentes do modelo capitalista, moderno, urbano e industrial. A sociedade do consumo e do mercado deve ser combatida. Assim como a soberania da técnica e da ciência. A gestão participativa e a cidadania ativa precisam ser construídas e fortalecidas.

Palavras-chave: Educação; Transformação; Participação

\begin{abstract}
Environmental destruction is consequence of many factors that include the process of modernity and the development of the capitalistic system. Critical environmental education has to work in the direction of new paradigms different from the capitalistic model and from the modernity and urban and industrial society. Consume and market has to be questioned together with the supremacy of the science and technical age. Participative governance and active citizenship have to be constructed and strengthened.
\end{abstract}

Keywords: Education; Transformation; Participation

\section{Introdução}

As civilizações não se desenvolvem apenas pelos seus recursos materiais, mas, principalmente pelos seus recursos culturais. Arriscar, inventar, tomar iniciativa, construir, questionar, participar são elementos culturais. A sobrevivência das civilizações deve-se principalmente à educação. As civilizações criaram ao longo da história diversas formas de escola e ensino. Podemos, portanto, concluir que o recurso humano mais relevante é a educação.

Nas comunidades tradicionais as pessoas viviam em propriedade comum da terra e a educação era responsabilidade de todos no próprio processo da vida. Tudo acontecia em harmonia com a natureza. $\mathrm{O}$ advento das técnicas e da propriedade privada rompeu com os valores tradicionais e desenvolveu os interesses individuais e a disputa pelo poder. Fato que também influenciou na educação.

\footnotetext{
${ }^{1}$ Mestre em Sociologia e Antropologia (UFRJ), Geografia (UFRJ) e Jornalismo (PUC-Rio). Coordenador do Sistema de Comunicação e da Secretaria Executiva do Mosaico de Unidades de Conservação da Mata Atlântica Central Fluminense (2009 - 2015).

E-mail: arcalama@gmail.com
} 
Freud afirmou que uma das fontes do sofrimento humano é derivada justamente dos relacionamentos construídos ao longo do processo civilizatório.

"Freud não compreende por que no relacionamento humano (terceira fonte do sofrimento), fomos tão malsucedidos, não tendo bastado para solucionar o problema nossos códigos e leis regulamentadores da conduta. Num amargo balanço das conquistas humanas, avaliando prós e contras. Freud admite que a chamada civilização é uma parte responsável por nosso inerente sofrimento e que seríamos mais felizes se voltássemos às condições primitivas. Retorno à natureza? Numa época em que o orgulho humano frente às suas conquistas parecia atingir um dos pontos culminantes, estas considerações adquirem particular relevo. E agora, esta conclusão para ecologista nenhum botar defeito. 'Parece que a subjugação das forças da natureza não trouxe mais felicidade' (Freud, 1977, Mal-estar na civilização. vol. XXI, p.107)" (CUNHA, 1992).

A civilização ocidental está em permanente crise. O problema está certamente na educação. O recurso primário cultural e ontológico não é a natureza e sim a educação. No entanto, foi a civilização ocidental que mais investiu nas escolas. Um ensino que, entretanto, concentrou suas forças nas tentações egoístas de explorar ao máximo a natureza e os outros seres. Uma educação diferenciada para cientistas e intelectuais e os apenas "alfabetizados" e submissos. Uma educação que divide os que tomam decisões e os que vivem de acordo com as regras estabelecidas. Necessitamos de uma educação que transmita as verdadeiras necessidades da vida e os valores nobres da justiça socioambiental. Antes de formarmos técnicos e cientistas temos que formar valores dignos e importantes para a convivência socioambiental. A ciência e a técnica que temos hoje nos colocam em perigo. Tudo por causa da educação irresponsável que coloca os conhecimentos científicos e técnicos como superiores e absolutos e encabeçada por poucos. Não adianta, portanto, multiplicarmos este modelo de ensino e convivência. $\mathrm{O}$ pensamento mecânico e superficial precisa ser eliminado. A educação não pode continuar formando seres apáticos e sim participativos. Necessitamos de uma educação que questiona sempre a razão da vida e do mundo. Nunca tivemos uma sociedade tão poderosa para transformar a natureza, nunca fomos tão rápidos e ao mesmo tempo nunca produzimos tanto desperdício e sujeira, junto com muita injustiça social. Precisamos de novos valores e novas ideias. Temos que questionar o que da ciência e da técnica é realmente útil. O sentido da vida é o elemento mais importante da educação. O ensino ocidental se baseia nas ideias de evolução, competição, interesses econômicos, conhecimento técnico e objetivo, hierarquias, poder, autoridade. Valores que são passados através do sistema de educação vigente, tanto para dominados como para dominadores. As disciplinas e as técnicas relacionadas têm como origem o mesmo centro de ideias e valores. Esse centro é que deve ser questionado e transformado. 
O mais importante é a busca pela felicidade geral, o amor e a liberdade. Nossa sociedade urbana e industrial afastou de nós a contemplação, a meditação, a poesia. Nosso lado emocional foi degradado pela necessidade de produzir e consumir cada vez mais e mais rápido. No entanto, a maioria dos problemas não é solucionado pela racionalidade mecânica e sim pelas emoções. Não se preocupar com ganhar dinheiro se tornou vulgar e ficar contemplando e dedicar tempo com poesia, literatura, divertimento é perder dinheiro. Até o exercício físico e o lazer são realizados de forma mecânica em academias de ginástica, clubes, shoppings, parques temáticos, resorts. Precisamos de uma reconstrução metafísica. As soluções não se encontram na organização, administração, economia. O desastre de nossa civilização moderna está muito bem expresso na forma em que usamos o território e nos objetos que inserimos nele (viadutos, edifícios, usinas, estacionamentos, cidades inteiras com pouca vegetação, monoculturas). Tudo resultado de uma educação desastrosa que passa valores inconsequentes. O ser humano é um filho da Terra e da terra. Não é o dono da terra em que pode sair arrasando o solo, a água e a vida. Cabe à educação transformar essa situação em que os elementos da natureza e a justiça socioambiental se tornam os verdadeiros valores sagrados. Quando lidamos com a terra e o trabalho, não podemos pensar em crescer a produção, aumentar a eficiência, reduzir os custos apenas. Existem outros valores e outras relações muito mais relevantes como a própria saúde, a paisagem bonita, a felicidade comum, a justiça socioambiental (SCHUMACHER, 1973).

O projeto conservador de educação ambiental é baseado numa visão liberal. Trata-se de uma educação que visa unicamente à transmissão de informações e os processos sociais e críticos ficam em segundo plano. A educação ambiental crítica, ao contrário, prioriza as discussões em torno das relações de poder e fortalecem a capacidade política das comunidades em relação às transformações no território.

"Essa educação ambiental que se está procurando balizar é crítica aos paradigmas cientificistas que informam a sociedade moderna urbano-industrial, ao seu modelo de desenvolvimento que se caracteriza em sua proposta de modernização que é conservadora, porque mantém o status quo (situação atual), e que procura, de acordo com sua racionalidade, direcionar uma compreensão sobre desenvolvimento sustentável. Esse fato caracteriza a noção de sustentabilidade como um campo de disputa. O caráter crítico buscado pretende deixar em evidência as relações de poder e dominação que engendram as sociedades contemporâneas" (GUIMARÃES, 2002: 82).

O modelo de desenvolvimento e progresso atual tem que ser rompido a favor de um novo paradigma de relação sociedade/natureza e de sociedade. A massificação cultural provocada pela mídia, principalmente da televisão e da internet, também precisa ser combatida com o fortalecimento de meios de comunicação e de informação 
alternativos e independentes. Contra a valorização da cultura e do modo de vida consumista.

O mercado não é a solução para a crise ambiental e cabe ao educador enfatizar isso, propondo a formação de uma nova sociedade. Necessitamos, portanto, de mudanças estruturais e partir para o verdadeiro conflito contra o modelo atual e os seus poderosos dominadores.

"Uma sociedade cada vez mais complexa, planetária, como a de nossos dias atuais, baseada em paradigmas fragmentários, individualistas, simplificadores da realidade, antagônicos a uma realidade complexa, caminha a passos largos para a degradação da qualidade de vida humana e planetária, para uma crise socioambiental de insolvência" (GUIMARÃES, 2002: 98).

A educação ambiental precisa trabalhar de forma interdisciplinar, complexa, dinâmica e transversal.

Figura 1: Educação Ambiental tem que ser crítica ao sistema e ao paradigma atual e atuar de forma interdisciplinar, multidisciplinar e transversal, indo além da instituição de ensino para um confronto.

\section{A EDUCAÇÃO AMBIENTAL DEVE SER TRATADA POR TODAS AS DISCIPLINAS DE FORMA:}

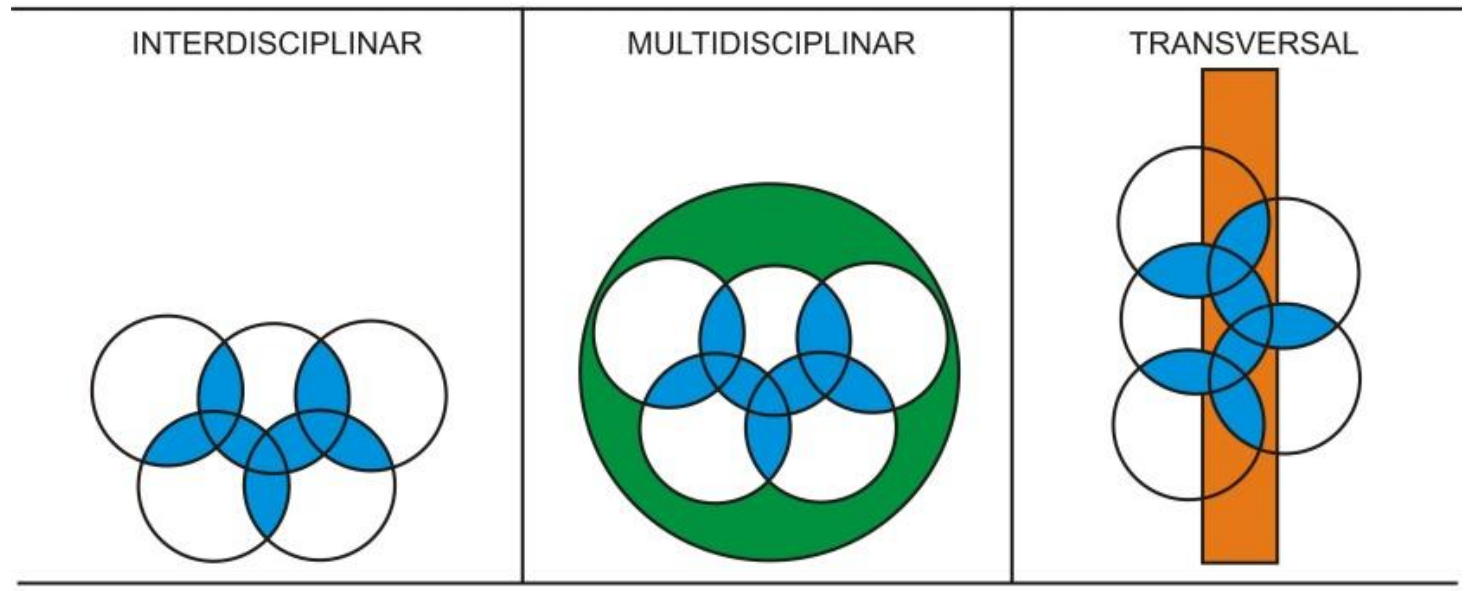

A EDUCAÇÃO AMBIENTAL NÃO É DISCIPLINA ESPECIFICA. DEVE SER INCLUIDA EM TODAS AS ATIVIDADES COMO FATORÉTICO E DE CIDADANIA. ATITUDES SUSTENTÁVEIS DEVEM FAZER PARTE DO COTIDIANO DAS INSTITUIÇŐES E DO COMPORTAMENTO DIÁRIO DOS INDIVÍDUOS. ALEI 9.795 DE 1999 TRAÇA AS DIRETRIZES DAEDUCAÇÃO AMBIENTAL NO BRASIL.

Fonte: O Autor

Criar, portanto, uma educação que compreenda a complexidade e seja protagonista de práticas criativas e críticas ao paradigma atual. A educação ambiental 
não pode ficar presa à instituição de ensino e sim enxergar a realidade social estabelecida na sociedade que necessita ser rompida. $\mathrm{O}$ pertencimento e o amor à natureza e aos outros cidadãos são elementos importantes nesse processo assim como a construção concreta da justiça socioambiental e isso requer estar pronto para desafios e confrontos.

\section{Material e Métodos}

As redes podem ser extremamente úteis na educação ambiental. Trata-se de um dispositivo prático extremamente importante. É uma oportunidade para se construir vivências de relações não hierárquicas. Construir assim estruturas descentralizadas a partir da cultura de cooperação e de participação. O fortalecimento das redes passa necessariamente pelo desenvolvimento de eventos regionais e locais e a criação de sites, publicações, rádios e TVs de protagonismo popular. Os princípios de horizontalidade e de autonomia precisam ser detonados na prática coletiva. Elementos essenciais são a cooperação e a co-evolução que leva à complexidade. Toda a organização deve ser participativa e articulada. O foco deve ser nos processos com destaque para acordos de convivência e de relações laterais. As redes devem ser sempre abertas às possíveis entradas e saídas de informações e permanentemente alimentadas e renovadas. O fluxo de informações é não linear e multidirecional, sendo assim dinâmica e instável. A autoorganização e a articulação das diferenças é outro ponto relevante das relações em rede (AMARAL, 2008).

O mais importante é estarmos rompendo com todas as formas de dominação e de subordinação presentes nas relações hierárquicas do sistema dominado pelo mercado e pelo Estado. Alguns conceitos chaves são:

- Dinâmicas de coletividade;

- Auto-organização;

- Inteligência coletiva;

- Governança horizontal;

- Distribuição da informação.

Apesar da proposta de auto-organização, as coordenações são necessárias assim como a sistematização dos processos. Esse é o papel do educador ambiental na comunidade que deve trabalhar para romper com as normas cotidianas verticais. $\mathrm{O}$ educador deve incentivar as dinâmicas de cooperação e de diálogo crítico. Os processos devem levar à confiança, ao respeito mútuo, à reciprocidade e à criação de compromissos. A rede é, antes de tudo, um processo contínuo, dinâmico, sistêmico de comunicação ativa.

O social e o ecológico necessitam estar sempre juntos. A Educação Ambiental deve trabalhar a valorização simbólica do território em conjunto com as esferas políticas e econômicas que estão presentes neste espaço geográfico. Os territórios são afetados pelo avanço dos interesses econômicos da indústria, dos agronegócios, da construção 
civil e do comércio. A Educação Ambiental precisa ressaltar em seu trabalho as contradições e os conflitos gerados por este modelo econômico de desenvolvimento. Trata-se de um modelo altamente excludente e as comunidades têm que se organizarem para resistirem e construírem alternativas para o uso do território e para a organização social.

"O simples avançar de uma sociedade que se pauta na expropriação, na acumulação de riqueza, na apropriação privada do que é gerado pela sociedade traz em si como lógica estruturante de suas relações elementos de desigualdade $\mathrm{e}$ elementos de dissociação entre sociedade e natureza. Desenvolvimento sustentável desta sociedade não existe. Não há possibilidade de você tornar sustentável aquilo que por definição é excludente e é profundamente utilitário do que a natureza oferece a nós como possibilidade de vida e a própria perpetuação da vida. A sustentabilidade tem que ser procurada em outro patamar de sociedade e não nesta" (Frederico Loureiro em entrevista para o I Congresso Goiano de Educação Ambiental agosto 2008).

Cabe ao educador ambiental articular-se ao máximo com os diversos movimentos sociais que atuam nos territórios e que resistem à expansão do mercado e da indústria capitalista. Movimentos que muitas vezes não se clamam de ambientais, mas que sem dúvida agem no território e lutam por justiça e, portanto, vão querer conquistar transformações no espaço geográfico e na própria organização social e econômica. A educação ambiental tem o papel de facilitar a cooperação nos processos de decisão. Toda sociedade tem seus mitos, produtos da imaginação coletiva e da história cultural. No entanto, esses valores devem ser trabalhados em conjunto com os conflitos gerados pela sociedade capitalista e devem ter destaque nos debates. A proteção ambiental está aliada ao Empoderamento político e à inclusão social. O capitalismo tem a tendência de transformar tudo em mercadoria procurando assim impor novos modos de vida, destruindo os tradicionais, a desterritorização e danos ambientais.

\section{Educomunicação}

A Educomunicação é uma estratégia nova e extremamente importante e eficiente para se criar o empoderamento popular e das comunidades através da comunicação. A implantação e o desenvolvimento de ações de Educomunicação se apresentam como recurso essencial com o objetivo de proporcionar informação, condições de participação e de transformações nos modos de produção. Existe uma estreita relação entre comunicação, educação e sustentabilidade. Produzir, gerir e disponibilizar de forma interativa e dinâmica a Educomunicação torna-se fator essencial para garantir a gestão 
participativa e sustentável do território. Ações que deverão ser replicadas em todas as regiões.

Trata-se da formação de jovens e crianças para a utilização da comunicação como ferramenta de intervenção e transformação. O material de Educomunicação deve ser produzido de forma coletiva e provocar o desenvolvimento de canais de fortalecimento da organização social. Processo que envolve a apropriação dos instrumentos de comunicação pelas comunidades. É necessário promover o diálogo permanente visando ações cooperativas e não competitivas. Promover assim a comunicação na perspectiva de seu potencial de educação incentivando a argumentação e a mobilização. Nesse sentido temos que aproximar as percepções socioambientais e valorizar as experiências humanas.

Muitos conflitos sociais estão associados a questões ambientais e necessitam serem discutidos e aliviados. Compreendemos como o principal agente da ação comunicativa e educativa as próprias comunidades. Estimular a reflexão e ações nas comunidades, elaborar materiais didáticos, estimular a disseminação de saberes e valores locais, incentivar a apropriação de meios de comunicação e a produção de informações pelas comunidades e promover estruturas de produção e gestão popular são caminhos essenciais para a proteção da biodiversidade e dos recursos hídricos em conjunto com a geração de renda de forma autônoma. O primeiro passo deve ser a compreensão da complexidade socioambiental do território e a formação de estratégias sustentáveis e integradas de desenvolvimento. Com isso, pretendemos criar e fortalecer o pertencimento que é a identificação da população com o território. A abordagem deve, portanto, ser transdisciplinar e trabalhar a valorização do diálogo social.

O objetivo é integrar de forma holística o físico, espiritual, intelectual e artístico. As atividades artísticas e artesanais são permanentemente valorizadas assim como os mitos e as lendas dos povos tradicionais. A capacidade de questionamento e de comunicação é sempre incentivada. O conceito de autoeducação é enfatizado na metodologia.

Através do sistema de comunicação do Mosaico de Unidades de Conservação da Mata Atlântica Central Fluminense desenvolvemos, nos anos de 2013 e 2014, a metodologia da Educomunicação. O resultado foi a criação de 12 Núcleos independentes de comunicação em comunidades, instituições de ensino e unidades de conservação. Esses núcleos produziram diversas reportagens e participaram de filmagens que estão presentes no site do Mosaico e nos programas da TV Mosaico (www.mosaicoentral.org.br).

\section{Resultados esperados com o desenvolvimento da Educomunicação}

Compreendemos a Educomunicação como um processo político que visa o desenvolvimento do pensamento crítico para a promoção de ações transformadoras e responsáveis de intervenção e gestão do espaço geográfico. Só a criação de sujeitos 
críticos e ativos promove a emancipação necessária para superar as injustiças e desigualdades sociais. Fator necessário também para evitar novos desastres ambientais e difundir atividades econômicas menos impactantes. É importante também estarmos influenciando os Projetos Políticos Pedagógicos das instituições de ensino do território e os projetos de educação ambiental das unidades de conservação.

\section{Conclusão}

A educação ambiental é um instrumento importante. No entanto, temos que trabalhar uma educação ambiental crítica e transformadora. Não podemos nos levar pela educação ambiental hipócrita. Presente, por exemplo, quando se incentiva a reciclagem de objetos tipo PET nas escolas. Proposta que acaba levando ao consumo de refrigerantes e outros objetos industriais. Da mesma forma, é hipócrita falar para o indivíduo economizar água enquanto que os grandes usuários de água são os responsáveis pelos agronegócios e a indústria que além de consumirem muito despejam resíduos que poluem os recursos hídricos e o solo e exploram a mão-de-obra, muitas vezes expulsando as populações tradicionais de seus territórios.

A educação ambiental deve promover a crítica ao sistema e levantar propostas de transformação. Deve incentivar os instrumentos de direito, legais e de controle social do território. Desenvolver meios de comunicação independentes em que as comunidades são protagonistas é outro aspecto essencial. Os laços de parceria e de relacionamento devem ser incentivados pelo educador ${ }^{2}$. Nesse processo os saberes populares precisam ser enfatizados e as comunidades mobilizadas para enfrentarem a força do mercado e do Estado, tornando-se assim protagonistas da emancipação e da transformação.

Cabe ao educador ambiental incentivar a participação da comunidade em outras instituições relevantes para o território como os comitês de bacia hidrográfica, os mosaicos de áreas protegidas, os conselhos municipais diversos e os de unidades de conservação próximas. A comunidade assim marca presença e se fortalece politicamente e influencia nas tomadas de decisões relacionadas ao território. É importante também que membros da comunidade saibam usar os diversos instrumentos que visualizam o território como os Sistemas de Informação Geográficos - poderem assim acompanhar e promover discussões sobre o uso do solo e as transformações impostas e desejadas. Cabe ao educador ambiental demonstrar a insustentabilidade do atual sistema social técnico, urbano e industrial que é passado na educação convencional como sendo o único caminho.

\footnotetext{
2 Uma educação renovadora e extremamente envolvida com as questões ambientais está sendo desenvolvida na Inglaterra pela Schumacher College em Devon que utiliza a metodologia do ensino holístico e já contou com a colaboração de Fritjof Capra, Vandana Shiva e James Lovelock. A instituição homenageia o autor alemão Ernst Friedrich Schumacher que escreveu "Small is Beautifaul" em 1973. A metodologia valoriza a cultura e o ambiente local. Questiona a economia contemporânea, a matriz energética e o consumo.
} 
O mais importante é destacarmos que o modelo civilizatório ocidental está em colapso, fato que vem junto com a degradação de meio ambiente e do desmantelamento das comunidades locais. Hoje temos a consciência dos limites globais. É necessário na educação ambiental o fato de encontrarmos encaixados em todos os processos sociais e ambientais presentes. Uma nova lógica de vida e de relação sociedade-natureza precisa ser construída.

\section{Bibliografia}

AMARAL, V. (2008). "REBEA: processos e desafios de horizontalização" in Revista Brasileira de Educação Ambiental, ${ }^{\circ}$ 3. Brasília.

CUNHA, H. P. (1992). "Ecologia: um retorno que mobiliza avanço" in Ecologia e Literatura, RJ: Tempo Brasileiro.

GUIMARÃES, M. (2002) "Sustentabilidade e Educação Ambiental” in CUNHA, S.B. e GUERRA, A.T. A Questão Ambiental: Diferentes Abordagens, RJ: Bertrand Brasil.

SCHUMACHER, E. F. (1973). Small is Beautiful: economics as if people mattered in (http://www.ditext.com/schumacher/small/small.html, 2016). 